ENCYCLOPEDDE Encyclopédie berbère

BERBERE

$2 \mid 1985$

2 | Ad - Ağuh-n-Tahlé

\title{
Ag-Māma Ag Sīdi
}

H. Claudot-Hawad

\section{OpenEdition}

Journals

Édition électronique

URL : http://journals.openedition.org/encyclopedieberbere/926

DOI : 10.4000/encyclopedieberbere.926

ISSN : 2262-7197

\section{Éditeur}

Peeters Publishers

\section{Édition imprimée}

Date de publication : 1 novembre 1985

Pagination : 261-262

ISBN : 2-85744-209-2

ISSN : 1015-7344

\section{Référence électronique}

H. Claudot-Hawad, «Ag-Māma Ag Sīdi », Encyclopédie berbère [En ligne], 2 | 1985, document A98, mis en ligne le 01 décembre 2012, consulté le 25 septembre 2020. URL : http://journals.openedition.org/ encyclopedieberbere/926; DOI : https://doi.org/10.4000/encyclopedieberbere.926

Ce document a été généré automatiquement le 25 septembre 2020

(c) Tous droits réservés 


\section{Ag-Māma Ag Sīdi}

\section{H. Claudot-Hawad}

1 Ag-Mama est le second fils de Kella, ancêtre fondatrice du clan dominant des Touaregs de l'Ahaggar, les Kel-Rela (Kdl yela), et de Sidi ag Mohammed el-Kheir, qui fut chef du pays dans la deuxième moitié du XviII ${ }^{e}$ siècle. Vers 1830 , le frère aîné d'Ag-Mama, Younès ag Sidi, qui avait succédé à son père, meurt ; Ag-Mama prend sa suite et devient à son tour amenukal* de l'Ahaggar (voir pour la succession et généalogie des chefs de l'Ahaggar : H. Claudot, 1982, La sémantique au service de l'anthropologie, p. 174). Au passage de l'explorateur Duveyrier en 1859, Ag-Mama, très âgé et aveugle, est décrit comme le "doyen des centenaires du Sahara» (Duveyrier, 1864, p. 368). Il est alors dans l'incapacité de gouverner et l'anarchie semble régner dans l'Ahaggar divisé entre l'autorité parcellaire des quatorze chefs de tribus nobles.

2 Comme son frère Younès, Ag-Mama a épousé une femme des Taïtoq et sous son règne, la paix a pu régner entre les deux clans rivaux. Cependant, les dissensions se réveillent au sujet de sa succession. Du vivant de ce chef déclinant, qui n'est pas en mesure de rallier les siens pour résister notamment aux attaques répétées des nomades arabes Chaâmba, une solution est envisagée et le choix porté sur un personnage, El-Hadj Ahmed ag El-Hadj El-Bekri, qui cumule trois qualités; celle d'être marabout donc auréolé d'un certain prestige ; d'être également étranger par son père qui est des Iforas (Ifōyas)*, ce qui l'exclut des inimitiés locales, tout en étant Kel Rela par sa mère; enfin d'être le fils aîné de la sœur aînée d'Ag-Mama, c'est-à-dire son héritier légitime selon la loi matrilinéaire revendiquée par certains. Cependant, le fils d'Ag-Mama, soutenu par les Taïtoq auxquels il se rattache par sa mère, réclame le pouvoir. Entre-temps, en 1861, Ag-Mama meurt. Les Taïtoq déclarent la guerre aux Kel Rela. Il s'ensuit une période trouble de rezzous réciproques, jusqu'à ce que le fils d'Ag-Mama, devenu chef des Taïtoq, abandonne ses ambitions de dominer la confédération de l'Ahaggar en écartant les Kel-Rela du pouvoir. A partir d'Ag-Mama, tous les chefs de la confédération de l'Ahaggar sont recrutés en voie matrilinéaire parmi les descendants de Kella. 


\section{BIBLIOGRAPHIE}

BENHAZERA M. Six mois chez les Touareg du Ahaggar, Alger, Jourdan, 1908, 233 p. (voir pp. 112-114).

DUVEYRIER H. Les Touareg du Nord, Paris, Challamel, 1864, 488 p. (voir pp. 368-369).

INDEX

Mots-clés : Touareg 